\title{
Style Matters
}

\section{New forms for references}

\author{
EDWARD HUTH
}

British Medical fournal, 1979, 1, 1697-1698

Four major clinical journals have recently published the Vancouver Declaration, "Uniform Requirements for Manuscripts Submitted to Biomedical Journals."1-4 This document represents an agreement among several journal editors that manuscripts submitted to them for publication should be prepared in accordance with specific requirements. The agreement further stipulates that the requirements about manuscripts stated in a journal's instructions to authors should not contradict any of the uniform requirements.

The details of style in the Vancouver Declaration apply to manuscripts, and the co-operating journals are not required to use any of the style details as their publication style. Nevertheless, the editors of some of the co-operating journals have decided to use most, or all, of the manuscript style details for their publication styles. The Annals of Internal Medicine is taking that step. Beginning in our July 1979 issue we shall use the form of references outlined in the Vancouver Declaration for all papers published in the journal. (This is the form used for the references at the end of this paper.) In January 1980 other journals and Index Medicus will begin to use the new forms.

\section{Producing standards for references}

We have received inquiries from several authors and editors about the origin of the new forms of bibliographical references and the rationale for their sequence and punctuation.

The story goes back a long way. For many years the American National Standards Committee on Library Work, Documentation, and Related Publishing Practices (known informally as Z39) has been preparing standards that define desirable formats and styles for technical and scientific publication. After earlier failures to establish a standard for bibliographical references, a new American National Standards Institute (ANSI) subcommittee, Subcommittee 4 on Bibliographic References, was established in April 1971. It drafted a standard that was finally accepted by the parent organisation and published in $1977 . .^{5}$

Bibliographical references have been presented in many widely different formats for many years. Among biomedical journals at least three styles have been used. The subcommittee sought to develop a standard that was based on rational principles and which could be applied uniformly to the forms of bibliographical references for a wide variety of documents and other published materials: scientific articles, books, patent documents, music,

\footnotetext{
Annals of Internal Medicine, American College of Physicians,

newspaper articles, and so on. The foreword to the new standard is pertinent:

"This standard encompasses many of the concepts being developed at the international level, such as the use of groups or "areas" of bibliographic elements and the use of a limited set of punctuation symbols related to those promulgated in the International Federation of Library Associations' International Standard Bibliographic Description for Monographs and Serials and the philosophy of bibliographic levels set forth in the United Nations Educational, Scientific and Cultural Organisation's UNISIST Reference Manual for Machine-Readable Bibliographic Descriptions. The ISBD rules of punctuation and format were not adopted in toto, because ISBD rules do not currently take into account the requirements for references ... of the different media."

The draft standard developed by the ANSI subcommittee was approved by 55 institutions and organisations, including the American Chemical Society, the American Institute of Physics, the American Society for Information Science, BioSciences Information Service (BIOSIS), the Council of Biology Editors, the Library of Congress, the National Academy of Sciences, and the National Library of Medicine.

\section{New forms for Index Medicus}

The story now shifts to the editors who met in Vancouver in January 1978 to draft their declaration. At that meeting we had to decide what form of bibliographical references would be established for manuscripts. Some of the journals represented in Vancouver had already agreed in 1970 to use the Index Medicus style for their published references. ${ }^{6}$

The 1970 agreement had, however, specified only forms for journal articles, books, and book chapters and not the forms for references to other kinds of documents that might be cited. Therefore, the decision was made in Vancouver to follow the established principle and to ask the National Library of Medicine (NLM) to develop a more comprehensive set of forms for references. The NLM, having endorsed the ANSI standard, decided to use the principles in the standard both to revise the form for references to journal articles and to prepare forms for references to other documents.

The forms developed by the NLM for use in Index Medicus follow broadly the sequence of data elements and the punctuation dictated by the ANSI standard. In this standard the bibliographical data are assigned to up to seven data groups: authorship, title, edition, imprint, physical description, series statement, and notes. References to journal articles include elements in three groups: authorship, title (both article title and journal title), and imprint (for journals this includes year, volume number, in some cases issue number, and pagination).

The standard specifies consistent use of punctuation to separate groups of data elements and data elements within each group. A period is placed at the end of each data group. The 
semicolon separates different bibliographical elements within a group and precedes volume-identification data.

For references to journal articles, the ANSI standard gives four different forms. Two of these are condensed forms that would not be satisfactory for use in Index Medicus. The first alternative form of journal article reference given in the standard is as follows:

Dunlap, Connie R. Cataloguing in Publication. Library Journal. 99 (18):2573-2578; 1974 October 15.

The second alternative form for the same reference is:

Dunlap, Connie R. Cataloguing in Publication. Library Journal. 1974 October $15 ; 99$ (18):2573-2578.

The NLM elected to base its style of references for journal articles on the second form. The NLM forms do not follow exactly the punctuation specified in the ANSI standard, and individual journals may choose to revise the punctuation in references submitted to them in the NLM (Vancouver) style.

The location of the year of publication is structurally related to how the bound volumes of a journal sit on a library shelf. The journal title stands for the journal in its continuing entirety; the year is the first logical division of the journal into its component parts; the volume is the next logical division within the year; and the issue number (in some cases) and then the page numbers of the journal article are the final divisions. This location of year is not a radical innovation; it has been used for some years by Excerpta Medica, the Lancet, and the BMF, three journals widely read in the medical community. There may be some visual confusion for readers between the year and the volume number, and some journals may use different type faces for different data elements in bibliographical references. The Annals of Internal Medicine will use bold-face type for the volume number, to enable readers to distinguish it from the year and the page numbers.

\section{Improving communication}

The NLM and the journals that will use its new forms for references are likely to be joined by other groups of scientific publishers in drawing on the logical principles of the new ANSI standard. If such standardisation is expanded by further agreements on symbols, abbreviations, and other style conventions, great steps will have been taken towards promoting clear and unambiguous communication among all scientific disciplines.

\section{References}

${ }^{1}$ International Steering Committee. Uniform requirements for manuscripts submitted to biomedical journals. Am Rev Respir Dis 1979;119:3-10.

2 International Steering Committee. Uniform requirements for manuscripts submitted to biomedical journals. $B r$ Med 7 1979;1:532-5.

3 International Steering Committee. Uniform requirements for manuscripts submitted to biomedical journals. Lancet 1979;1:428-31.

4 International Steering Committee. Uniform requirements for manuscripts submitted to biomedical journals. Ann Intern Med 1979;90:95-9.

5 American National Standards Institute. American national standard for bibliographic references, Z39.29-1977. New York: American National Standards Institute, 1977.

6 Huth EJ. Standard forms for references. Ann Intern Med 1970;72:140-1.

(Accepted 27 April 1979)
What percentage of breast lumps are ultimately found to be benign? What percentage of all the malignant ones have a five-or ten-year survival rate?

The percentage of breast lumps that will prove to be benign or malignant on histological examination depends mainly on the particular population seen. In a predominantly young group of women-for example, those attending a family planning clinic-most lumps will be benign. Indeed, less than $1^{\circ}{ }_{0}$ of breast cancers are seen in women aged 30 years or less. In contrast a doctor with mainly elderly patients will see a far greater proportion of women with malignant disease, so it is quite a good rule that a lump in the breast in a postmenopausal woman will probably prove malignant. Taking the average outpatient population in Britain, about one-quarter of all women presenting to the surgical clinics with a localised lump in the breast will prove to have a carcinoma.

Prognosis depends on the stage at which the carcinoma is seen and treated. A patient with a small primary tumour in the breast without affected axillary lymph nodes has something in the region of an $80 \%$ chance of 10-year survival. If one to three lymph nodes are affected the prognosis becomes much more guarded, dropping to about $60 \%$ five-year survival, and if there is heavy involvement of the axillary nodes (four or more proving positive on histological examination) then the five-year survival drops to the region of $30 \%$. With advanced local disease, the prognosis must also be guarded, though occasionally long survivals follow radiotherapy. If the patient is seen with clinical or radiological evidence of widespread dissemination the prognosis must be very guarded indeed, though occasional survivals for several years may be seen in those who are sensitive to hormones.

What is the treatment and prognosis of arachnoiditis optochiasmatica?

Great caution is needed in diagnosing arachnoiditis optochiasmatica. The diagnosis is always tentative until confirmed by exploration, which can be justified only when there is strong clinical evidence to suspect compression. This condition is rare in the West. ${ }^{12}$ Recent reports from Japan, however, suggest that there may be a definite relation between arachnoiditis optochiasmatica and some form of retrobulbar neuritis as evidenced by the confirmation of the diagnosis by surgery in a considerable number of patients who initially presented with signs of retrobulbar neuritis. ${ }^{34}$ Arachnoiditis optochiasmatica is a chronic affection and occurs secondarily to inflammation, which may be low grade in nature, or arachnoidal adhesions. It may follow meningitis, trauma, or haemorrhage or be associated with tuberculosis, syphilis, or sarcoid. It has been reported in older children and in young and middle-aged adults of both sexes. It mainly affects the basal cisterns, and there is pronounced thickening of the arachnoid often containing accumulation of fluid. The proliferation of connective tissue bands leads to adhesions which cause compression of the optic nerve and the chiasm. The olfactory nerve and the carotids may also be affected. The disease is accompanied by a multiplicity of symptoms. Patients may initially complain of headache and blurred vision. In the early stages the ocular symptoms may be confined to one eye only. Characteristically the visual field defects are quite irregular and depend on the varied extent of the changes in the arachnoid, the circulating disturbances caused by them, and a spread of the inflammatory process to the optic nerve itself. The visual loss is frequently progressive. An optic atrophy develops in about half of the cases, which is not usually equally pronounced on both sides. Papilloedema may be present in some cases. Paralysis of the extraocular muscles may be an infrequent feature. There may be neighbourhood signs and symptoms if the disease has affected the nearby structures. Results of general neurological examinations are usually negative, and routine skull radiographs are normal. Carotid arteriography may show angulation or distortion of the ophthalmic artery, and pneumoencephalography may show obliteration of the chiasmic cistern in the absence of a space-occupying lesion. Treatment is surgical, adhesions must be freed and any accumulated fluid drained away. Prognostication is difficult before operation since there is no definite criteria to distinguish the patients who will respond to surgery from those who. will not. Visual improvement has been reported in about half of the operated cases. ${ }^{3-5}$

\footnotetext{
Walsh F B, and Hoyt, W F, in Clinical Neuro-ophthalmology, vol 3, 3rd edn 2100. Baltimore, Williams and Wilkins, 1969. puber, A, Eye Signs and Symptoms in Brain Tumors, ed F C Blodi, 3rd edn, p 260. Saint Louis, Mosby, 1976.

Imachi, J, et al, Fapanese Fournal of Ophthalmology, 1964, 8, 137.

+ Shimo-Oku, M, et al, in: Neurogenetics and Neuro-ophthalmology. 5th International Congress, Nijmegen, 1977. Documenta Ophthalmologica Proceedings Series, ed A F Dentman and J R M Cruysberg, vol 17, p 175. The Hague, Junk, 1978 .

${ }^{5}$ Dickmann, G H, Cramer, F H, and Kaplan, A D, fournal of Neurosurgery, 1951,
8, 355.
} 